FORMAÇÃO DE PROFESSORES PARA O ENSINO DAS RELAÇÕES ÉTNICO RACIAIS: UM ESTUDO COMPARATIVO ENTRE PUBLICAÇÕES CIENTÍFICAS NO PARÁ (INDÍGENA) E NA BAHIA (AFRODESCENDENTE)

\author{
TEACHER TRAINING FOR TEACHING RACIAL ETHNIC RELATIONSHIPS: A \\ COMPARATIVE STUDY BETWEEN SCIENTIFIC PUBLICATIONS IN PARÁ \\ (INDIGENOUS) AND BAHIA (AFRODESCENDENTE)
}

\author{
FORMACIÓN DE PROFESORES PARA LA ENSEÑANZA DE RELACIONES ÉTNICAS \\ RACIALES: UN ESTUDIO COMPARATIVO ENTRE PUBLICACIONES CIENTÍFICAS EN \\ PARÁ (INDÍGENA) Y BAHIA (AFRODESCENDENTE)
}

Karolina Carvalho do Amarante Universidade Federal do Oeste do Pará - Brasil

Gilberto César Lopes Rodrigues

Universidade Federal do Oeste do Pará - Brasil

\begin{abstract}
Resumo: O presente estudo tem como tema a formação de professores para o ensino das relações étnicoraciais. A pesquisa foi motivada pela intenção de comparar a produção científica sobre o tema em duas regiões diferentes geográfica e etnicamente, sendo uma predominantemente indígena e, a outra, afrodescendente, na perspectiva de desvelar o que publicações acadêmicas dessas regiões examinam e sugerem sobre a formação de professores no campo das relações étnico-raciais. A questão norteadora foi: o que revistas acadêmicas de educação na área de formação de professores para as relações étnico-raciais publicam em regiões de presença predominantemente de afrodescendentes e o que publicam em regiões predominantemente indígenas. O que são examinados e sugeridos para essa formação? Escolheu-se as regiões de Santarém-PÁ e Vitória da Conquista-BA por reunirem grande número de grupos étnicos indígenas e quilombolas, respectivamente, e revistas acadêmicas na área da educação em universidades locais (Exitus - UFOPA e Práxis Educacional - UESB). Trata-se de uma pesquisa de exploração bibliográfica cujo levantamento dos dados consistiu na busca das produções científicas nas revistas no período entre 2011 a 2020 centrados nos marcadores "formação de professores" e "relações étnico-raciais". Inferimos que predominantemente as produções encontradas abordam a adequação curricular para o ensino das relações étnico-raciais para a implementação das Diretrizes Curriculares Nacionais para a Educação das Relações Étnico-Raciais à luz da Lei $\mathrm{n}^{\circ} 10.639 / 03$, nenhuma sugere técnicas ou métodos para a formação e todas produções abordavam afrodescendentes.
\end{abstract}

Palavras chave: Formação de professores; Educação para as relações étnico raciais; Revista Exitus e Praxis Educacional. 


\begin{abstract}
This study is about the training of teachers for ethnic-racial relations. The research was motivated by the intention to compare the scientific production on the subject in two different regions geographically and ethnically, one being predominantly indigenous and the other, Afro-descendant, with the perspective of unveiling what academic publications from these regions examine and suggest about teacher training for ethnic-racial relations. The guiding question was: what academic education magazines in the area of teacher training for ethnic-racial relations publish in regions predominantly afro-descendants and what they publish in predominantly indigenous regions. What are examined and suggested for this training? The regions of Santarém-PÁ and Vitória da Conquista-BA were chosen because they brought together a large number of indigenous and quilombola ethnic groups, respectively, and for having academic magazines in the field of education at local universities (Exitus - UFOPA and Praxis Educacional - UESB). This study involved research of bibliographic exploration whose data collection consisted of the search for scientific productions in this magazines in the period between 2011 and 2020 centered on the markers "teacher training" and "ethnic-racial relations". We infer that predominantly the described productions deal with the curricular adequacy for the teaching of ethnic-racial relations for the implementation of the National Curriculum Guidelines for the Education of Ethnic-Racial Relations in the light of Law $n^{\circ} 10.639$ / 03, there is no suggestion of techniques or methods for the teaching of ethnic-racial relations and all productions aimed at people of African-descent.
\end{abstract}

Keywords: Teacher training; Education for ethnic racial relations; Exitus and Praxis Educacional Magazine.

Resumen: Este estudio tiene como tema la formación de maestros para la enseñanza de las relaciones étnicoraciales. La investigación fue motivada por la intención de comparar la producción científica sobre el tema en dos regiones geográficas y étnicas diferentes, una predominantemente indígena y la otra de ascendencia africana, con la perspectiva de revelar qué publicaciones académicas de estas regiones examinan y sugieren sobre la formación de docentes en el campo de las relaciones étnico-raciales. La pregunta guía fue: ¿qué publicaciones de educación académica en el área de capacitación docente para las relaciones étnico-raciales publican en regiones con predominantemente afrodescendientes y qué publican en regiones predominantemente indígenas? ¿Qué se examinan y se sugieren para esta capacitación? Se eligieron las regiones de Santarém-PA y Vitória da Conquista-BA porque tienen una gran cantidad de grupos étnicos indígenas y quilombolas, respectivamente, y revistas académicas en el campo de la educación en las universidades locales (Exitus - UFOPA y Praxis Educacional - UESB). Es una investigación de exploración bibliográfica cuya recopilación de datos consistió en la búsqueda de producciones científicas en el período comprendido entre 2011 y 2020 centrado en los marcadores "formación docente" y "relaciones étnicoraciales". Inferimos que predominantemente las producciones encontradas abordan la adecuación curricular para la enseñanza de las relaciones étnico-raciales para la implementación de las Directrices Curriculares Nacionales para la Educación de las Relaciones Étnico-Raciales a la luz de la Ley no 10.639 / 03, ninguna sugiere técnicas o métodos para el formación y todas las producciones dirigidas a afrodescendientes.

Palabras clave: Formación de profesores; Educación para las relaciones raciales étnicas; Revista Exitus y Praxis Educacional.

\title{
Introdução
}

O presente texto resulta de uma pesquisa sobre formação de professores para o ensino das relações étnico-raciais. O objetivo foi o de comparar produções científicas sobre essa formação relativas a conteúdo abordado e sugestões apresentadas para formação de professores para relações étnico-raciais. Escolheu-se duas regiões no país etnicamente diferentes, sendo uma predominantemente indígena (Pará) e, a outra, afrodescendente (Bahia) no intuito de verificar se 
essa diferença étnica direciona as publicações, ao recorte temático adotado e, se há sugestões de ações no campo da formação desses professores. A questão norteadora foi: o que revistas acadêmicas de educação publicam sobre formação de professores para o ensino das relações étnicoraciais em regiões de presença predominantemente afrodescendentes e o que publicam em regiões predominantemente indígenas. O que são examinados e sugeridos para esse tipo de formação? Escolheu-se as regiões de Santarém-PÁ e Vitória da Conquista-BA, além do recorte étnico, por publicarem revistas acadêmicas na área da educação em universidades locais (Exitus - UFOPA e Práxis Educacional - UESB).

A Revista Práxis Educacional é um periódico trimestral, eletrônico, do Programa de PósGraduação em Educação (PPGEd), da Universidade Estadual do Sudoeste da Bahia (UESB). Publica artigos inéditos resultantes de pesquisas científicas, além de resenhas de livros. Seu objetivo central é divulgar pesquisas e estudos vinculados ao campo da educação, desenvolvidos por pesquisadores de diferentes contextos educacionais do Brasil e do exterior. A Revista Exitus, é um periódico de publicação contínua, da Universidade Federal do Oeste do Pará-UFOPA. Sua meta é incentivar o debate e propiciar a divulgação da produção científica, como veículo de diálogo permanente entre os profissionais da educação. O estudo foi desenvolvido exclusivamente por exploração bibliográfica via rede web e envolveu o método comparativo entre os dois ambientes de coleta de dados utilizados, as revistas Exitus (UFOPA) e Práxis Educacional (UESB).

Delimitou-se como recorte temporal publicações entre 2011 a 2020 em ambas as revistas, devido a Exitus ter surgido em 2011 e equilibrar temporãmente a comparação e envolveu produções em dossiês temáticos e artigos em fluxo contínuo. A estratégia para o desenvolvimento da coleta de dados envolveu três etapas: na primeira coletou-se artigos a partir do descritor "formação de professores" que retornou cento e sessenta e cinco produções. Na segunda filtrou-se produções obtidas combinando os descritores "formação de professores" e "relações étnico-raciais", através da leitura de títulos, palavras-chave e resumo, da qual nove foram selecionados. Por último realizouse a leitura integral dos artigos, sendo três na Revista Exitus e seis na Revista Práxis educacional.

\section{A formação de professores para a Educação das relações étnico raciais}

O debate sobre a formação de professores, tanto a inicial como a continuada, está presente em inúmeros pesquisas acadêmicas, desde teses e dissertações, a artigos científicos entre outros. Tais estudos procuram contribuir, cada qual a seu modo, para a melhoria da qualidade educacional e ao alcance de objetivos socialmente referenciados. 
Dentre as problemáticas que circundam a temática formação de professores, estão presentes estudos que buscam responder ao conflito entre o que a formação tem proposto no currículo e as lacunas dessa formação presentes na execução (MARTINS; DUARTE 2010). Isso condiz com o recorrente dilema entre a relação teoria e prática, que assolam os cursos de formação docente e as práticas profissionais. Nesse sentido, é premente que a formação busque superar tal conflito, pois teoria e prática se inter-relacionam, ambas são inseparáveis e essenciais na ação educativa (SAVIANI, 2019)

O espaço escolar, como legítimo representante da sociedade envolvente, é um ambiente complexo, permeado de tensões e conflitos e apresenta inúmeras realidades que instigam a formação de professores e impactam a formação destes em todas as áreas, inclusive para o ensino das relações étnico-raciais.

Os primeiras passos da formação de professores no Brasil, conforme Saviani (2009), inicia com a criação das Escolas de Primeiras Letras, que tornava obrigatório aos professores a instrução, com formação a partir do "modelo dos conteúdos culturais-cognitivos" (SAVIANI, 2009, p. 148), centrados no domínio dos conteúdos disciplinares se estendendo entre 1827-1890. Entre 1890-1932 ocorre a expansão das Escolas Normais com a criação de uma escola-modelo anexa à Escola Normal - em que a formação perpassava pelos conteúdos curriculares com ênfase nas práticas de ensino. Mais tarde, entre 1932-1939 amplia-se o foco no currículo dos cursos de formação de professores, com o advento dos Instituto de Educação que organizando uma formação que valorizasse não apenas o ensino, mas a pesquisa. Passou-se a pensar um currículo condizente aos "modelos pedagógicosdidáticos".

Entre 1939-1971 ocorre a implantação dos Cursos de Pedagogia e de Licenciatura e a consolidação do modelo das Escolas Normais, a partir da elevação ao nível universitário dos Institutos de educação do Distrito Federal e de São Paulo. A partir do decreto-lei no 1.190 , de 4 de abril de 1939 os cursos de formação de professores foram organizados para as escolas secundárias a partir do modelo " $3+1$ ", sendo dedicados três anos para estudos dos conteúdos cognitivos e um ano para formação didática. Ocorre entre 1971-1996 a substituição da Escola Normal pela Habilitação Específica de Magistério, a partir do golpe militar de 1964, que mudou o texto da lei $\mathrm{n}^{\circ}$ 5.692/71 modificando a denominação dos ensinos primário e médio, alterando respectivamente para primeiro e segundo grau. A partir dos movimentos dos educadores, em 1980, vê-se a reformulação dos cursos de Pedagogia e licenciaturas, por meio dos ideários das pedagogias contra hegemônicas que lutaram pela identidade profissional da docência, colocando as bases para a incorporação do ensino das relações étnico-raciais. 
No período entre 1996-2006 ocorre o advento dos Institutos Superiores de Educação, Escolas Normais Superiores e o novo perfil do Curso de Pedagogia, em que a Lei ${ }^{\circ}$ 9.394/96 introduziu como alternativa aos cursos de pedagogia e licenciatura os institutos superiores de educação e as Escolas Normais Superiores com cursos aligeirados e com baixo custo. Saviani (2009) pontua a partir dos processos ocorridos ao longo desses períodos um quadro de descontinuidade e de precarização da formação docente.

Com a promulgação da lei $n^{\circ} 10.639 / 03$ que alterou a Lei $n^{\circ} 9.394 / 96$ no art. 26 - A, foi tornado obrigatório nos estabelecimentos de ensino fundamental e médio, oficiais e particulares, o ensino sobre a História e Cultura Afro-Brasileira. A alteração da lei é fruto das lutas do movimento negro, que se tornou um importante avanço para o reconhecimento e valorização dessas culturas na história da nação brasileira e superação de uma visão eurocêntrica no ensino. O Brasil, apesar de multicultural, também é um país racista e, apesar de toda uma mobilização por parte dos movimentos sociais na criação de políticas para o combate e enfrentamento das questões étnico raciais, ainda vivemos em meio a ideologias de branqueamento, espalhadas nos diferentes espaços da sociedade e que precisam ser superadas em vista do reconhecimento de nossa pluralidade cultural, que não deve ser argumento para as desigualdades sociais, mas instrumento de equalização das diferenças e avanços na construção de um país mais igualitário e justo.

Outro importante avanço, apesar de entender que só a obrigatoriedade da lei não garante a implementação nos espaços educativos, se encontra na Lei $n^{\circ} 11.645 / 2008$ que modifica o art. 26A, da LDB, incluindo nos estabelecimentos de ensino fundamental e de ensino médio, públicos e privados, a obrigatoriedade do estudo da história e cultura afro-brasileira e indígena. Portanto, a história e cultura indígena passam a ser reconhecidas no texto da lei, a fim de serem implementadas nos currículos da educação básica superando a perspectiva integracionista.

No ano de 2004, o Ministério da Educação (MEC) por meio da Secretaria de Educação Continuada, Alfabetização e Diversidade SECAD (extinta em 2019), no intento de "[...] corrigir injustiças, eliminar discriminações e promover a inclusão social e a cidadania para todos no sistema educacional brasileiro" (BRASIL, 2004, p. 5), elaboram, junto a diálogos com o movimento negro, as Diretrizes Curriculares Nacionais para a Educação das Relações Étnico-Raciais e para o ensino de História e Cultura Afro-brasileira e Africana, norteando as ações e implementações da lei nos currículos escolares.

Destaca, o referido documento, que o termo raça é entendido e utilizado com sentido político e social, de valorização da cultura africana (BRASIL, 2004). Biologicamente o termo raça não existe, mas "existe na cabeça dos racistas e de suas vítimas” (MUNANGA, 2005-2006, p. 52). O termo étnico, usado na expressão étnico-raciais, refere-se as tensas relações devido a “[ [...] diferenças 
na cor da pele e traços fisionômicos, [...] à raiz cultural plantada na ancestralidade africana, que difere em visão de mundo, valores e princípios das de origem indígena, europeia e asiática (BRASIL, 2004, p. 13)

De acordo com essas diretrizes “a educação das relações étnico-raciais impõe aprendizagens entre brancos e negros, trocas de conhecimentos, quebra de desconfianças, projeto conjunto para construção de uma sociedade justa, igual, equânime" (BRASIL, 2004, p. 14). Logo, trata-se de políticas de combate ao racismo e todas as formas de discriminação em vista do fim da desigualdade social e racial, instigando os espaços escolares e não escolares a reeducação das relações étnicoraciais. Desse modo, escola e professores são chamados a abordar o tema.

[...] tais políticas têm, também, como meta o direito dos negros, assim como de todos cidadãos brasileiros, cursarem cada um dos níveis de ensino, em escolas devidamente instaladas e equipadas, orientados por professores qualificados para o ensino das diferentes áreas de conhecimentos; com formação para lidar com as tensas relações produzidas pelo racismo e discriminações, sensíveis e capazes de conduzir a reeducação das relações entre diferentes grupos étnico-raciais, ou seja, entre descendentes de africanos, de europeus, de asiáticos, e povos indígenas (BRASIL, 2004, p. 10-11).

De acordo com a Resolução CNE/CP-2/2015, que define as Diretrizes Curriculares Nacionais para a formação inicial em nível superior (cursos de licenciatura, cursos de formação pedagógica para graduados e cursos de segunda licenciatura) e para a formação continuada, estabelece em seu Artigo $5^{\circ}$ dentre os princípios

II - a formação dos profissionais do magistério (formadores e estudantes) como compromisso com projeto social, político e ético que contribua para a consolidação de uma nação soberana, democrática, justa, inclusiva e que promova a emancipação dos indivíduos e grupos sociais, atenta ao reconhecimento e à valorização da diversidade e, portanto, contrária a toda forma de discriminação.

Observa-se no trecho acima, o enfoque ao reconhecimento e à valorização da diversidade, repudiando qualquer forma de discriminação. O referido documento ressalta no artigo $6^{\circ}$ que a formação deve contemplar "VI - as questões socioambientais, éticas, estéticas e relativas à diversidade étnico-racial, de gênero, sexual, religiosa, de faixa geracional e sociocultural como princípios de equidade".

Para subsidiar a implantação das diretrizes para a educação das relações étnico-racial, é publicado, em 2006, as Orientações e Ações para a Educação das Relações Étnico-Raciais (BRASIL, 2006). Aborda esse documento que a formação docente deve visar uma pedagogia antirracista que prime pela diversidade, comprometida politicamente com uma educação plural e democrática. Busca-se combater a formação generalista, e volta-se a implementar um currículo que 
capacite os profissionais da educação a compreensão das singularidades presentes no espaço escolar, superando a visão homogênea de ensino que recusa à diferença.

Em suma, o ensino, ou mesmo a abordagem do tema das relações étnico-raciais na escola é um dever legal e objetiva educar, ou seja, apaziguar, disciplinar, as relações históricas assimétricas entre as diversas manifestações étnicas no país. Apesar da indiscutível formação social brasileira que envolve índios, negros, afrodescendentes, europeus, orientais e outros povos e culturas, somente recentemente foi disciplinado e incentivado a educação para as relações étnico-raciais, fato que torna importante levantarmos o que pesquisadores da área tem abortado em seus exames e o que tem proposto para mover o ensino dessas relações.

\section{Produções científicas sobre formação de professores para o ensino das relações étnico raciais}

A seguir, serão apresentadas as produções científicas encontradas nos ambientes de coleta de dados, revista Exitus (UFOPA) e Revista Praxis Educacional (UESB), através da descrição da metodologia de coleta e da apresentação sintética das referidas pesquisas.

O quadro 1 apresenta os resultados gerais das produções obtidas a partir do descritor "formação de professores" nas referidas revistas lócus da pesquisa.

Quadro 1: Total geral de produções sobre formação de professores nas Revistas Exitus/UFOPA e Práxis educacional/UESB (2011-2020)

\begin{tabular}{|r|c|}
\hline \multicolumn{1}{|c|}{ Revistas } & Total das publicações \\
\hline Exitus/UFOPA & 54 \\
\hline Práxis Educacional/ UESB & 111 \\
\hline \multicolumn{2}{|r|}{ Total } \\
\hline
\end{tabular}

Fonte: Amarante e Rodrigues (2020)

Nas análises por ano nas revistas pesquisadas, os dados apresentados demonstram que em 2019 houve um volume significativo de produções referentes a temática da formação de professores na Revista Exitus/Ufopa. Senso que na revista Práxis Educacional/UESB, foi verificado o maior volume de publicações no ano de 2018, como demonstrado a seguir. 


\section{PRODUÇÕES SOBRE FORMAÇÃO DE \\ PROFESSORES ENCONTRADAS POR ANO \\ NAS REVISTAS EXITUS/UFOPA E PRÁXIS \\ EDUCACIONAL/UESB (2011-2020)}

—EXITUS/ UFOPA —PRÁXIS EDUCACIONAL/ UESB

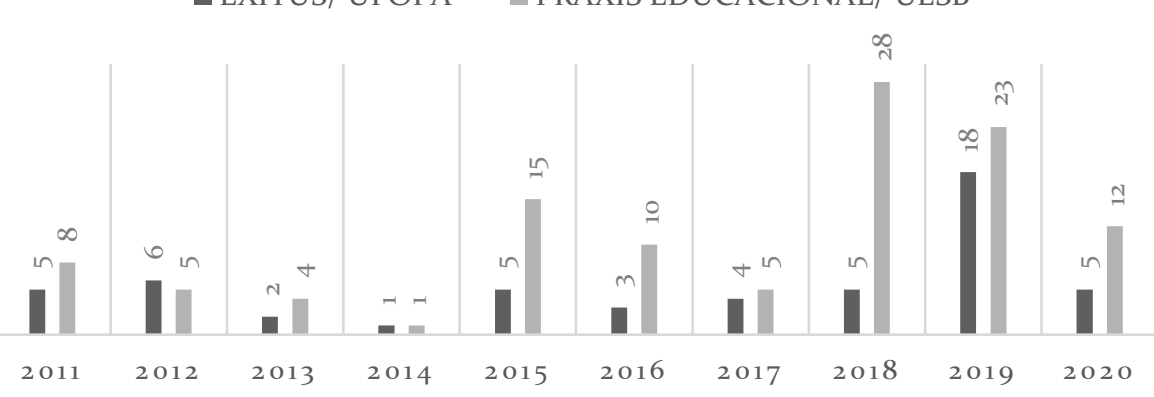

Gráfico 1: Produções sobre formação de professores encontradas por ano (2011-2020)

Fonte: Amarante e Rodrigues (2020)

Partindo para a segunda etapa, filtramos as produções por meio da inclusão do descritor “relações étnico-raciais” fazendo a leitura dos resumos das produções. Na Revista Exitus/UFOPA foram obtidos 4 (quatro) trabalhos em formato de artigo, que após leitura integral dos estudos, detectamos somente 3 (três) artigos correspondentes ao nosso objeto em estudo. Na Revista Práxis Educacional/UESB somente 6 (seis) correspondiam ao nosso objeto em estudo, sendo há 4 (quatro) dossiês temáticos e 2 (dois) artigos.

No quadro abaixo, agrupamos as produções acadêmicas encontradas em cada revista, ressaltando o ano de publicação, as palavras-chaves e a localização das produções em que foi realizada a pesquisa.

Quadro 2: As produções sobre formação de professores e relações étnico-raciais encontradas na Revista Exitus/UFOPA e Práxis Educacional/UESB (2011-2020)

\begin{tabular}{|c|c|c|c|c|}
\hline Revista & Ano & Título & Palavras-chave & Local \\
\hline \multirow{3}{*}{ 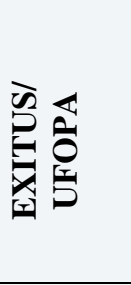 } & 2019 & $\begin{array}{l}\text { CURRÍCULO DES-OCULTO: outras } \\
\text { vozes, outras epistemologias }\end{array}$ & $\begin{array}{l}\text { Currículo. Educação das Relações } \\
\text { Étnico-Raciais. Prática docente. }\end{array}$ & UFES \\
\hline & 2019 & $\begin{array}{l}\text { ENTRE OMISSÃO E PRECONCEITO } \\
\text { RACIAL: discurso-acontecimento }\end{array}$ & $\begin{array}{l}\text { Currículo. Relações étnico- } \\
\text { raciais. Círculo de Bakhtin. }\end{array}$ & UFLA \\
\hline & 2020 & $\begin{array}{l}\text { "HISTÓRIA PRA NINAR GENTE } \\
\text { GRANDE": currículo e formação de } \\
\text { professores quilombolas }\end{array}$ & $\begin{array}{l}\text { Ancestralidade. Educação Escolar } \\
\text { Quilombola. Diferença. }\end{array}$ & UNEB \\
\hline \multirow{3}{*}{ 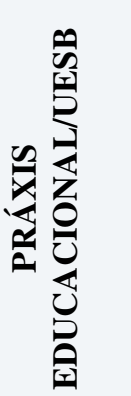 } & 2014 & $\begin{array}{l}\text { A ausência/presença das relações étnico- } \\
\text { raciais nos currículos dos cursos de } \\
\text { pedagogia: o caso da Unesp/Marília }\end{array}$ & $\begin{array}{l}\text { Currículo. Educação. Curso de } \\
\text { pedagogia. Formação de } \\
\text { professores/as. Relações étnico- } \\
\text { raciais. }\end{array}$ & UNESP \\
\hline & 2015 & $\begin{array}{l}\text { Limitações da formação docente } \\
\text { evidenciadas na prática pedagógica: trato } \\
\text { com o tema das relações Étnico-Raciais }\end{array}$ & $\begin{array}{l}\text { Formação continuada. Prática } \\
\text { educativa. Relações étnico- } \\
\text { raciais. }\end{array}$ & UESB \\
\hline & 2017 & $\begin{array}{l}\text { As políticas de ações afirmativas para a } \\
\text { população negra: a Lei } 10.639 / 03 \text { e seus } \\
\text { dispositivos legais }\end{array}$ & $\begin{array}{l}\text { Ações afirmativas. Educação das } \\
\text { relações étnico raciais. } \\
\text { População negra. }\end{array}$ & Unimontes \\
\hline
\end{tabular}




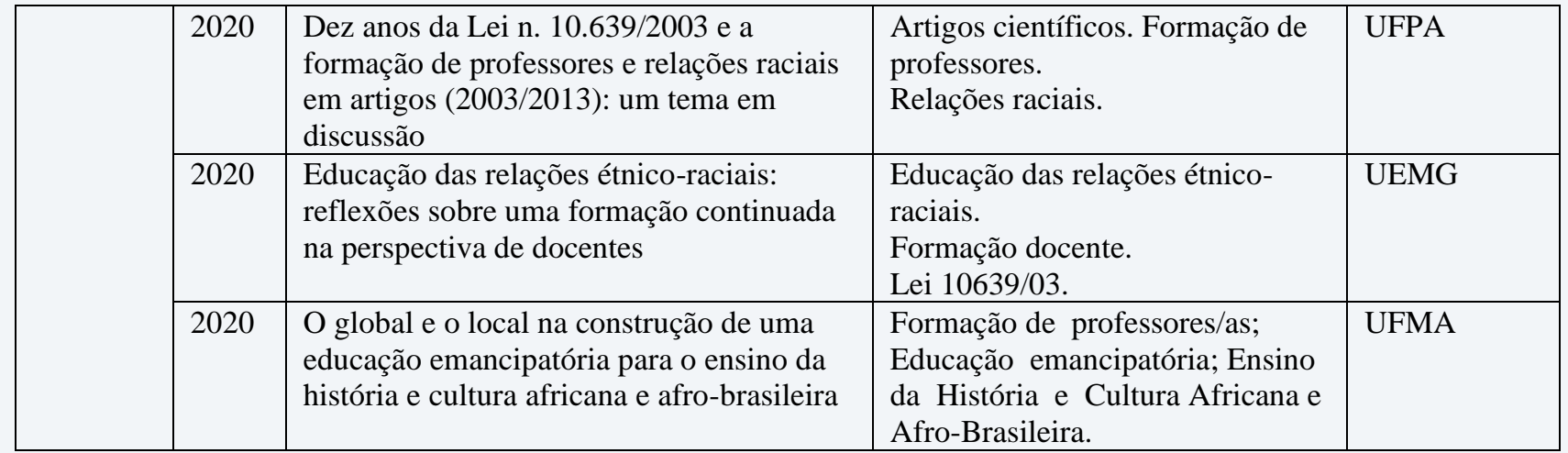

Fonte: Amarante e Rodrigues (2020)

Em nossas análises, as produções acadêmicas encontradas na Revista Exitus/UFOPA dialogam o tema da formação de professores para as relações étnico-raciais a partir da categoria currículo, abordando a questão étnico-racial presente na grade curricular dos cursos de licenciaturas, assim como nas propostas de formação continuada de professores.

De Araújo e Dantas (2019) em pesquisa intitulada "Currículo des-oculto: outras vozes, outras epistemologias" abordam a categoria currículo e práticas pedagógicas, com o objetivo duplo de refletir sobre o currículo predominante na educação brasileira e propor práticas pedagógicas que protagonizem a Educação das Relações Étnico-Raciais. Como ponto de partida de suas investigações indagam "Por que é que achamos que a diferença é um problema? Por que ela não é simplesmente um fato da realidade?" (De Araújo; Dantas, 2019, p. 150-151). Para isso, discutem as propostas de formação de professores/as a partir da disciplina Educação das Relações ÉtnicoRaciais (ERER), criada em 2017 pela Universidade Federal do Espirito Santo, inicialmente como disciplina optativa, passando a ser obrigatória para todos os cursos de licenciatura, com carga horária de 60 horas e ministrada por três docentes com formação e experiência na área da ERER. A pesquisa se propõe a analisar o componente curricular da referida disciplina, especificamente as propostas dos conteúdos programáticos (referencial teórico e fundamentos filosóficos) de uma das docentes que ministram o curso. Tal conteúdo está estruturado em quatro eixos: aspectos sócio-históricos; aspectos culturais e estéticos; África e conhecimento da diáspora; propostas e práticas pedagógicas. Além disso, analisam a proposta curricular do ensino médio, a partir da disciplina de Filosofia em uma instituição estadual (região metropolitana de Curitiba - PR), no ano de 2016 e outra federal no Instituto Federal do Espírito Santo - Campus de Linhares (Ifes), no ano de 2018. Relatam as experienciais curriculares nas duas instituições no trato com as relações étnico-raciais e filosofias de origem africana. Diante disso, consideram que as discussões sobre a Educação das Relações étnico-raciais nos currículos de licenciaturas, apesar da baixa carga horária, são cruciais para compreensão das práticas pedagógicas que incitem a reflexão sobre os currículos da educação básica. 
A pesquisa de Lobo, Villarta-Neder e Ferreira (2019) denominada "Entre omissão $e$ preconceito racial: discurso-acontecimento" partem dos pressupostos epistemológicos do campo bakhtiniano, com o intuito de problematizar o lugar das discussões sobre as questões étnico-raciais nos currículos voltados para a formação de professores de línguas. As situações-problemas que norteiam esta pesquisa refletem: em que medida os currículos tematizam discussões que ancoram construções/práticas discursivas sobre raça/etnia e problematizam as representações sociais? Que bases epistemológico-axiológicas podem sustentar uma proposição de um currículo que efetivamente contribua para a formação de professores de línguas? Como os sujeitos-futuros professores se constituem a partir e por meio dos currículos? Como implicar sujeitos-futuros professores de línguas para um trabalho com as relações étnico-raciais? A pesquisa envolveu 25 alunos do curso de graduação em Letras - modalidade licenciatura - e 3 professores de escolas públicas, do curso de extensão ofertado em um curso de formação de professores. Dentre os resultados da pesquisa, os autores enfatizam a importância do currículo a partir de uma abordagem discursiva que promova o enfretamento do racismo velado, em que o processo de formação de professores de línguas possibilitem um espaço para posicionamentos críticos, reflexivos e responsáveis sobre as relações étnico-raciais.

Oliveira (2020) aborda em sua pesquisa "História pra ninar gente grande: currículo e formação de professores quilombolas" a educação escolar quilombola a partir da formação de professores, com o objetivo de defender uma possiblidade de construção curricular fundada no binômio ancestralidade e diferença, a partir da experiência de formação docente, construída na parceria entre universidade e escola, visando a valorização de profissionais de educação de uma escola quilombola, bem como a construção de práticas formativas que acionem a diferença como potência. A pesquisa envolveu diálogo entre professores de educação básica e pesquisadoras através do dispositivo metodológico denominado de Grupos de Experiência (GE). Os conceitos de currículo, formação e diferença foram tratados pelo viés pós-colonial e pós-estrutural. O momento de encontro com os professores buscou valorizar a autonomia docente, ao invés de apontar lacunas nas práticas realizadas. A pesquisa ressalta a importância de construir currículos negros, voltados para a leitura da realidade das comunidades quilombolas. O processo formativo dos/as professores/as deve ser constituído de práticas curriculares que discutam sobre a ancestralidade, fortalecimento de vínculos com a comunidade, valorização dos profissionais experientes no contexto quilombola, vinculados aos valores, crenças e saberes construídos coletivamente.

As produções acadêmicas encontradas na revista Práxis Educacional/UESB abordam a formação para as questões étnico-raciais analisando também currículos da formação inicial de 
professores, na sua implementação e discussão nessa formação. Além da reflexão dessas formações nas práticas pedagógicas e discussões na formação continuada.

Cardoso e de Castro (2014) apresentam o estudo intitulado "A ausência/presença das relações étnico-raciais nos Currículos dos cursos de pedagogia: o caso da Unesp/Marília” com o objetivo de analisar os planos de ensino (ementas, programas) e os projetos pedagógicos da Unesp de Marília, com vistas à educação para as relações étnico-raciais, entre 1963 e 2011. Trata-se de um trabalho que integra uma pesquisa de mestrado, financiada pela FAPESP (Fundação de Amparo à Pesquisa do Estado de São Paulo) que tem como título “A formação de professores/as para a educação das relações étnico-raciais: limites e possibilidade no curso de pedagogia da Unesp de Marília (1963-2011'”. O estudo busca responder as seguintes questões: a) as relações étnico/raciais foram privilegiadas na formação de professores/as no curso de Pedagogia da Unesp de Marília? b) Como os Planos de Ensino e o Projeto Político Pedagógico do curso de Pedagogia da Unesp de Marília, ao longo de sua trajetória, abordou a temática racial? Para responder as essas indagações, as autoras utilizam como estratégias metodológicas pesquisa documental e revisão bibliográfica, organizando a pesquisa através três eixos temáticos sendo: Eixo 1- Currículo, por meio de contextualização dos diferentes autores e correntes teóricas a partir da perspectiva pós-critica; Eixo 2 - termos e conceitos referentes ao debate sobre as relações raciais no Brasil e; Eixo 3 - formação de professores/as para a educação das relações raciais com base na história das reivindicações do movimento Negro e do campo jurídico Lei n. 10.639/03 (BRASIL, 2003) e da Resolução n.1, de 10 de junho de 2004 (BRASIL, 2004), do Plano Nacional para a implementação da Lei n. 10.639/03 (BRASIL, 2003) e da Resolução 01/2006 que institui Diretrizes para o Curso de Pedagogia (BRASIL, 2006). A ênfase da análise está direcionada às disciplinas a partir de 2003, por se tratar do ano em que foi sancionada a Lei n. 10.639/03 (BRASIL, 2003) que torna obrigatório o Ensino da História e Cultura Africana e Afro-Brasileira em todo sistema de ensino. As autoras consideram, ao final do estudo, que a ausência, no currículo de formação de professores sobre as relações étnico raciais, é um dos principais entraves da implementação da Lei n. 10.639/03 nas escolas. Desse modo, afirmam, que se faz necessário a discussão na formação docente nos documentos norteadores pedagógicos do curso de forma ampla.

A produção denominada "Limitações da formação docente evidenciadas na prática pedagógica: trato com o tema das relações Étnico-Raciais” de autoria de Souza; Crusoé e Moreira (2015) se propõe a realizar um estudo sobre as limitações da formação docente evidenciadas na prática pedagógica no trato com o tema das relações Étnico-Raciais, tomando como referência sentidos atribuídos pelas educadoras aos projetos pedagógicos que tratam sobre a Cultura Afrobrasileira e Africana. O estudo indaga: Que lugar ocupam os saberes e conhecimentos dos 
estudantes, na prática pedagógica? Que lugar as diferenças culturais ocupam na prática pedagógica? Que práticas devem ser desenvolvidas para contemplar as diferenças? Trata-se de uma pesquisa empírica, realizada em uma escola municipal destinada aos Anos Finais do Ensino Fundamental (6 ${ }^{\circ}$ ao $9^{\circ}$ ano), na cidade de Ipiaú/BA, que há mais de 08 anos realiza projetos pedagógicos sobre as questões Afro-brasileiras. O estudo demonstrou que na referida escola houve a inserção da disciplina Diversidade Cultural com Enfoque na Cultura Afro-brasileira no currículo escolar. Tal disciplina, condiz com a preocupação da escola em implementar as Lei $n^{\circ} 10.639 / 03$ e Lei $\mathrm{n}^{\circ}$ 11.645/08 para sua efetivação. A técnica de coleta de dados foi realizada por meio de entrevistas semi-estruturadas com uma professora e a diretora da escola, a fim de identificar na fala das entrevistadas as limitações na prática docente com a temática em questão. Os resultados da pesquisa demonstram que a iniciativa de se trabalhar a temática Étnico-Racial na escola, emergiu do contexto de preconceitos e discriminação no espaço escolar e da vontade de uma das entrevistadas de materializar na escola os estudos que obteve sobre afro-descendência. Os resultados apontam para a necessidade da formação continuada de professores, reelaboração do currículo escolar a fim de melhor compreender o mito da democracia racial e suas implicações na atualidade.

O artigo de Cardoso (2017) versa sobre “As Políticas de Ações Afirmativas para a População Negra: A Lei 10.639/03 e seus dispositivos legais”. O interesse pelo estudo se justifica pelo seu objetivo de analisar a implementação das Diretrizes Curriculares Nacionais para a Educação das Relações Étnico-Raciais (DCNERER) nos cursos de formação docente de uma instituição pública de ensino superior no norte de Minas Gerais. A pesquisa foi realizada por meio da pesquisa documental e de entrevistas semiestruturadas em uma IES pública no norte de Minas Gerais. Os sujeitos envolvidos foram: gestores da Pró-Reitoria de Ensino, de Extensão e de Pesquisa - Unidades Administrativas, os coordenadores dos cursos de Licenciatura em Artes-Música, ArtesTeatro, Artes-Visuais, História, Letras e Pedagogia, e quatro professores de cada curso, a fim de analisar as ações que vem sendo desenvolvidas pela IES, no sentido de atender as DCNERER. Os resultados da pesquisa apontam que as DCNERER não foram ainda institucionalizadas na Estrutura Curricular dos cursos de licenciatura analisados e se encontram em fase de implementação. Porém, a pesquisa revelou que as DCNERER vêm sendo implementadas pelas ações docentes, como ações pontuais, desenvolvidas nas disciplinas em que trabalham, por opção pessoal, por opção política, por compreender a necessidade de se trabalhar com essa temática na formação inicial de professores, por ser pesquisador na área, dentre outros motivos.

A pesquisa "Dez Anos da Lei N. 10.639/2003 e a Formação de Professores e Relações Raciais em Artigos (2003/2013): Um tema em discussão”, autoria Coelho; de Brito (2020) tem por objetivo analisar a literatura especializada sobre a temática formação de professores e relações 
raciais, no período de 2003 a 2013, com foco nos artigos produzidos em revistas com qualificações atribuídas entre A1 a B5 a partir da qualificação registrada no ano de 2015. O estudo se propõe a investigar em que medida os artigos conferiram visibilidade a temática, promoveram a premência do enfoque à questão da diversidade nos processos de formação de professores. Os artigos foram submetidos a critérios de análise, do qual empreendeu 33 artigos analisados no corpus documental. O aporte metodológico foi amparado em algumas técnicas da Análise de Conteúdo Bardin (2016). Portanto, o estudo torna-se fundamental por se tratar de um estado do conhecimento referente a temática formação de professores e relações raciais, trazendo trabalhos que tratam deste objeto de estudo, e que, subsidiará novas pesquisas.

O estudo de Melgaço; de Brito; da Silva (2020) intitulado "Educação das Relações ÉtnicoRaciais: Reflexões sobre uma Formação Continuada na perspectiva de docentes" tem por objetivo analisar o II Curso de Aperfeiçoamento em História da África e das Culturas Afro-Brasileiras, oferecido pelo programa “Ações Afirmativas”, da Faculdade de Educação da Universidade Federal de Minas Gerais, em 2009, considerando seus reflexos nos saberes profissionais e nas práticas pedagógicas dos (as) docentes cursistas que lecionam na cidade mineira de Juatuba. O estudo de abordagem qualitativa, utilizou-se de pesquisa exploratória com vista a explanar e problematizar conceitos referentes a temática Educação das relações étnico-raciais (ERER). A estratégia investigativa foi o estudo de caso e pesquisa documental no projeto de formação continuada de professores pela Universidade Federal de Minas Gerais em parcerias com a Secretaria Municipal de Educação e o Programa Ações Afirmativas. A pesquisa contextualiza a importância de abordar a temática da ERER nos cursos de formação docente, em especial a formação continuada, pela reflexão nesses espaços da formação inicial e das práticas pedagógicas. Os autores pontuam em suas considerações que a formação realizada no curso de aperfeiçoamento, contribuíram de forma significativa para que as práticas pedagógicas dos sujeitos da pesquisa fossem condizentes com as propostas emitidas pelas DCN-ERER.

Regis; Neris; Rodrigues (2020) propõem em seu artigo, “O Global e o Local na construção de uma Educação Emancipatória para o ensino da História e Cultura Africana e Afro-Brasileira”, refletir sobre possibilidades da formação de professores em uma perspectiva de educação crítica e emancipatória. O estudo baseia-se em uma perspectiva crítica-emancipatória de educação, fundamentada na pedagogia de Paulo Freire. O ponto de análise parte dos trabalhos de campo realizados por dois projetos de pesquisa vinculados ao NIESAFRO-UFMA e os projetos e as ações realizados em escolas de Educação Básica com a participação de estudantes da LIESAFRO-UFMA, devido sua contribuição na prática de uma educação emancipatória que se apoia em pressupostos críticos e reflexivos. O fio condutor é o debate da relação entre escalas global e local na produção 
de conhecimento e formas de intervenção no mundo, na qual são constituídos espaços subalternos de poder, saber e modos de fazer, característico do atual momento de globalização contemporânea. Nessa perspectiva, reflete-se sobre a inserção do conhecimento local nos currículos de Moçambique e suas possíveis contribuições para a implementação da Lei nº 10.639/2003 no Brasil, uma vez que partem da mesma necessidade de romper com a lógica do currículo único e eurocêntrico.

\section{Considerações finais}

Esse texto apresenta um exame, ainda introdutório, sobre o que publicações acadêmicas das regiões de Santarém-PÁ e Vitória da Conquista-BA, nas revistas Exitus e Praxis Educacional, respectivamente, examinam e sugerem sobre a formação de professores para as relações étnicoraciais. Foi constatado que tais pesquisas buscam problematizar o currículo de formação de professores e qual papel a educação das relações étnico-raciais desempenha nessas formações (inicial e continuada) e nas práticas pedagógicas.

Em que pese o aumento significativo nas produções científicas brasileiras referente a formação de professores relacionadas ao tema das relações étnico-raciais desde a criação da Lei ${ }^{\circ}$ 10.639/2003, a pesquisa demonstrou, a partir da análise das produções científicas nos periódicos da Revista Exitus/UFOPA e Práxis Educacional/UNESB, que ainda há um número reduzido de pesquisas voltadas a essa problemática.

Das cento e sessenta e cinco produções levantadas nos dois periódicos referentes à formação de professores, apenas nove discutiam a respeito da temática formação de professores para a educação das relações étnico-Raciais. Todas, relacionadas a História da Cultura Africana e Afrobrasileira, abordando questões pertinente, destacadas nas DCNERER (BRASIL, 2004), como discriminação, preconceito, racismo, mito da democracia racial, descolonização do currículo, etc., abrangendo variadas regiões. No caso da revista Práxis Educacional/UESB, as publicações selecionadas eram todas voltadas ao tema formação de professores para as relações étnico-raciais das populações afrodescendentes. Paradoxalmente, nas publicações referentes a revista Exitus/UFOPA não há a presença de pesquisa vinculadas a educação para as relações étnico-raciais voltadas as populações indígenas, apesar de estar em região de predominância indígena.

Observamos que a maioria dos trabalhos buscou investigar a formação dos professores para o ensino das relações étnico-raciais a partir dos currículos, projetos pedagógicos e planos de ensino nas universidades atreladas a problematização da formação inicial de professores e da implementação das DCNERER (ARAÚJO; DANTAS 2019; (LOBO; VILLARTA-NEDER; FERREIRA 2019; CARDOSO; CASTRO 2014; CARDOSO, 2016). As demais focam em 
formações continuadas, em parcerias entre universidade e escolas para a temática vista em (OLIVEIRA, 2020; MELGAÇO; BRITO; SILVA 2020; REGIS; NERIS; RODRIGUES 2020), uma relacionada a prática pedagógica em (SOUZA; CASTRO MOREIRA, 2015) e uma revisão na literatura referente a implementação da Lei no 10.639/03, vista em (COELHO; BRITO, 2020).

Os resultados obtidos mostraram que as publicações buscavam problematizar o currículo de formação de professores à luz de sua adequação a legislação procurando compreender qual papel a educação das relações étnico-raciais desempenha nessas formações (inicial e continuada) e nas práticas pedagógicas. Tais estudos apontam para a adequação curricular nessas formações, em vista da implementação das diretrizes sobre a Educação para as Relações Étnico-Raciais com vista a superação de um currículo que negligencia as diferenças e suas consequências, como o racismo e a discriminação, mas não abordam sugestões de práticas e métodos para aprimorar essa formação.

Nesse sentido, o estudo bibliográfico comparativo possibilitou a imersão nas pesquisas do coletivo de estudiosos e que demonstraram problemáticas importantes a respeito da implementação das discussões sobre a Educação das relações étnico-raciais. Apontam também para a necessária investigação nos currículos de formação de professores a fim de possibilitar uma educação fundamentada nos princípios da diversidade cultural.

\section{REFERÊNCIAS}

AMARANTE, Karolina C.; RODRIGES, Gilberto. C. L. Cadernos de Campo. Santarém-PA: UFOPA, 2020.

ARAUJO, Débora Cristina de; DANTAS, Luís Thiago Freire. CURRÍCULO DES-OCULTO: outras vozes, outras epistemologias. Revista Exitus, Santarém/PA, Vol. 9, No 4, p. 147 - 175, Out/Dez 2019. Disponível em: 〈http://dx.doi.org/10.24065/2237-9460.2019v9n4ID1015>, acessado em 25 de março de 2020.

BRASIL, Ministério da Educação (MEC). Diretrizes Curriculares Nacionais para a Educação das Relações Étnico-Raciais e para o Ensino da História e Cultura Afro-Brasileira e Africana. Brasília: MEC, 2004.

BRASIL, Ministério da Educação (MEC). Orientações e Ações para a Educação das Relações Étnico-Raciais. Brasília: SECAD, 2006, p. 31-74.

BRASIL. Lei N. 10.639 de 9 de janeiro de 2003. Altera a Lei N. 9.394/1996, que estabelece as diretrizes e bases da educação nacional, para incluir no currículo oficial da Rede de Ensino a obrigatoriedade da temática "História e Cultura Afro-brasileira", e dá outras providências. Diário Oficial da República Federativa do Brasil. Brasília, DF, 9 jan. 2003. Disponível em: <http://www.planalto.gov.br/ccivil_03/LEIS/2003/L10.639.htm>. Acesso em: 07 abril de 2020

BRASIL. Lei N. 11.645, de 10 de março de 2008. Altera a Lei N. 9.394, de 20 de dezembro de 1996, modificada pela Lei N. 10.639, de 9 de janeiro de 2003, que estabelece as diretrizes e bases da educação nacional, para incluir no currículo oficial da rede de ensino a obrigatoriedade da 
temática "História e Cultura Afro-Brasileira e Indígena".Disponível em:

<http://www.planalto.gov.br/ccivil_03/_Ato2007-2010/2008/Lei/L11645.htm>. Acesso em: 07 de abril de 2020.

BRASIL. Ministério da Educação. Resolução no 2, de $1^{\text {0 }}$ de julho de 2015. Brasília: MEC. 2015. Disponível

em:<http://portal.mec.gov.br/index.php?option=com_docman\&view=download\&alias=17719 res-cne-cp-002-03072015\&category_slug=julho-2015-pdf\&Itemid=30192>. Acesso em: 02 abr 2020.

CARDOSO, Ivanilda Amado; CASTRO, Rosane Michelli de. A ausência/presença das relações étnico-raciais nos currículos dos cursos de pedagogia: o caso da Unesp/Marília. Práxis Educacional, [S.1.], v. 11, n. 18, p. 91-115, nov. 2014. ISSN 2178-2679. Disponível em: http://periodicos2.uesb.br/index.php/praxis/article/view/802. Acesso em: 30 abr. 2020

CARDOSO, Zilmar Santos. As políticas de ações afirmativas para a população negra: a Lei 10639/03 e seus dispositivos legais. Práxis Educacional, [S.1.], v. 13, n. 24, p. 284-308, nov. 2016. ISSN 2178-2679. Disponível em: http://periodicos2.uesb.br/index.php/praxis/article/view/942 . Acesso em: 01 maio 2020. doi: https://doi.org/10.22481/praxis.v13i24.942.

COELHO, Wilma de Nazaré Baía; DE BRITO, Nicelma Josenila Costa. Dez anos da lei n. 10.639/2003 e a formação de professores e relações raciais em artigos (2003/2013): um tema em discussão. Práxis Educacional, [S.1.], v. 16, n. 39, p. 19-42, abr. 2020. ISSN 2178-2679.

Disponível em: <http://periodicos2.uesb.br/index.php/praxis/article/view/6358 > . Acesso em: 03 maio 2020. doi: https://doi.org/10.22481/praxisedu.v16i39.6358.

GOMES, Nilma Lino. Relações Étnico-Raciais, Educação e Descolonização dos Currículos.

Currículo sem Fronteiras, v.12, n.1, pp. 98-109, Jan/Abr 2012. Disponível em:<

http://www.curriculosemfronteiras.org/vol12iss1articles/gomes.pdf $>$ Acesso em: 08 de maio de 2020.

LOBO, Dalva de Souza; VILLARTA-NEDER, Marco Antonio; FERREIRA, Helena Maria. Entre omissão e preconceito racial: discurso-acontecimento. Revista Exitus, Santarém/PA, Vol. 9, No 4, p. 176 - 203, Out/Dez 2019. Disponivel em: <http://dx.doi.org/10.24065/22379460.2019v9n4ID1009>, acessado em 20 de março de 2020.

MARTINS, L. M.; DUARTE, N. (org.). Formação de professores: limites contemporâneos e alternativas necessárias (online). São Paulo: Editora UNESP; São Paulo: Cultura Acadêmica, 2010

MELGAÇO, Paulo Henrique Maia; BRITO, José Eustáquio de; SILVA, Santuza Amorim da. Educação das relações étnico-raciais: reflexões sobre uma formação continuada na perspectiva de docentes. Práxis Educacional, [S.1.], v. 16, n. 39, p. 43-71, abr. 2020. ISSN 2178-2679. Disponível em: 〈http://periodicos2.uesb.br/index.php/praxis/article/view/6359>. Acesso em: 03 maio 2020. doi: https://doi.org/10.22481/praxisedu.v16i39.6359.

MUNANGA, Kabengele. Algumas considerações sobre "raça", ação afirmativa e identidade negra no Brasil: fundamentos antropológicos. REVISTA USP, São Paulo, n.68, p. 46-57, dezembro/fevereiro 2005-2006. Disponível em: <http://www.revistas.usp.br/revusp/article/view/13482>. Acesso em: 30 de maio de 2020.

OLIVEIRA, Iris Verena. "HISTÓRIA PRA NINAR GENTE GRANDE” 1: currículo e formação de professores quilombolas. Revista Exitus, Santarém/PA, Vol. 10, № 1, p. 1- 30, Edição 
Especial, 2020. Disponível em:< http://dx.doi.org/10.24065/2237-9460.2020v10n0ID1139>, acessado em 20 de abril de 2020.

REGIS, K. E.; NERIS, C. S. C.; RODRIGUES, S. J. Dias. O global e o local na construção de uma educação emancipatória para o ensino da história e cultura africana e afro-brasileira. Práxis Educacional, [S.1.], v. 16, n. 39, p. 91-114, abr. 2020. ISSN 2178-2679. Disponível em: <http://periodicos2.uesb.br/index.php/praxis/article/view/6361 >. Acesso em: 03 maio 2020. doi: https://doi.org/10.22481/praxisedu.v16i39.6361.

SAVIANI, Dermeval. Formação de professores: aspectos históricos e teóricos do problema no contexto brasileiro. Revista brasileira de educação, v. 14, n. 40, p. 143-155, 2009. Disponível em: < https://doi.org/10.1590/S1413-24782009000100012 > Acesso em: 05 de maio de 2020, às $23: 21$

SAVIANI, Dermeval. Pedagogia histórico-crítica, quadragésimo ano: novas aproximações. Campinas, SP: Autores associados, 2019.

SOUZA, Maicelma Maia; CASTRO Nilma Margarida; MOREIRA, Nubia Regina. Limitações da formação docente evidenciadas na prática pedagógica: trato com o tema das relações ÉtnicoRaciais. Práxis Educacional, [S.1.], v. 12, n. 21, p. 339-363, out. 2015. ISSN 2178-2679. Disponível em: <http://periodicos2.uesb.br/index.php/praxis/article/view/874>. Acesso em: 01 maio 2020.

\section{SOBRE OS AUTORES:}

\section{Karolina Carvalho do Amarante}

Mestranda em Educação pela Universidade Federal do Oeste do Pará. Integrante do grupo de pesquisa "História, Sociedade e Educação no Brasil-Histedbr-UFOPA e do Grupo de Pesquisa e Estudos em "Indigenismo, sociedades e Educação na Amazônia - ISSEAM. E-mail:

karol_mak@yahoo.com.br iD http://orcid.org/0000-0003-3505-0940

\section{Gilberto César Lopes Rodrigues}

Doutor em Educação, professor adjunto nos programas de graduação e pós-graduação em Educação da Universidade Federal do Oeste do Pará e do Programa de Pós-graduação em Educação Escolar Indígena em rede entre UEPA-UFOPA-UFPA-UNIFESSPA. Coordenador do Grupo de Pesquisa e Estudos em "Indigenismo, sociedades e Educação na Amazônia - ISSEAM. Email: gilberto.rodrigues@ufopa.edu.br

(iD) http://orcid.org/0000-0002-3960-5440 